\title{
Review Article \\ Role of Nanofibers in Encapsulation of the Whole Cell
}

\author{
Sudarshan Sahu $\mathbb{D}^{1},{ }^{1}$ Avinash Sharma, ${ }^{1}$ Soham Mukherjee $\mathbb{D}^{1},{ }^{1}$ Deepak Kumar $\mathbb{D}^{2}{ }^{2}$ \\ Fatih Sen $\mathbb{D}^{3},{ }^{3}$ Rupak Nagraik $\mathbb{D},{ }^{1}$ and Avvaru Praveen Kumar $\mathbb{D}^{4}$ \\ ${ }^{1}$ Faculty of Applied Sciences and Biotechnology, Shoolini University, Solan, 173229 Himachal Pradesh, India \\ ${ }^{2}$ Department of Pharmaceutical Chemistry, School of Pharmaceutical Sciences, Shoolini University, Solan, \\ 173229 Himachal Pradesh, India \\ ${ }^{3}$ Department of Biochemistry, University of Dumlupınar, 43000 Kütahya, Turkey \\ ${ }^{4}$ Department of Applied Chemistry, School of Applied Natural Science, Adama Science and Technology University, PO Box 1888, \\ Adama, Ethiopia
}

Correspondence should be addressed to Avvaru Praveen Kumar; drkumar.kr@gmail.com

Received 13 April 2021; Revised 20 August 2021; Accepted 27 October 2021; Published 24 November 2021

Academic Editor: Subrata Mondal

Copyright (c) 2021 Sudarshan Sahu et al. This is an open access article distributed under the Creative Commons Attribution License, which permits unrestricted use, distribution, and reproduction in any medium, provided the original work is properly cited.

\begin{abstract}
In the field of biomaterial research, the electrospinning device is now used to manufacture nanofibers that can be used to encapsulate whole microorganisms such as bacterial cells, funguses, viruses, and even spores. The nanofiber encapsulated cells will have greater significance in the coming future because of their wide variety of applications in various fields. Nanofibers act as microorganism reservoir systems that enhance their properties such as viability, controlled release of products, biomedical applications, and bioremediation. The effect of electrostatic forces on a droplet of liquid polymer or polymer solution is based on electrospinning. Electrospun nanofibers act as ideal native extracellular matrices for microorganisms and have also had a tremendous advantage in drug delivery systems where modern research is still underway. During electrospinning, nearly all microorganisms may be inserted into a polymer matrix that forms a composite nanofiber. The evolution in electrospinning technique over the past few decades has become promising. New ideas have been generated to enhance the techniques and improve the overall applications and properties of nanofibers. This technique has been transformed by the advent of the electrospinning machine. The electrospun nanofibers can be chemically characterized by a wide variety of procedures such as scanning electron microscopy (SEM), transmission electron microscopy (TEM), thermogravimetric analysis (TGA), X-ray diffraction (XRD), and Fourier-transform infrared spectroscopy (FTIR). Electrospinning has various applications, for example, in wastewater treatment, tissue engineering, food industry, drug delivery, agriculture, and cosmetics. Nanofiber encapsulation of microorganisms increased the shelf life of the microorganisms; the cells remain viable for months. It also helps in the control release of bacterial products. The present review demonstrates the role of nanofiber in the encapsulation of the whole cell.
\end{abstract}

\section{Introduction}

The biological material has to be encapsulated in a dry form to conserve its activity for various important applications. For this to happen, one has to go for the complete organism encapsulation. For example, there has been a significant recent increase in the use of bacterial viruses as an alternative to bacterial antibiotics (phase therapy) and as genetic delivery vectors (viral and nonviral vectors) [1-3]. Focus on nanofiber production has relied on the manufacture of fibers using numerous processing techniques such as draw- ing [4], template synthesis $[5,6]$, phase separation [7], selfassembly [8], and electrospinning [6-9]. The immobilization of different types of cells is advantageous in comparison to the free cells [10]. The immobilization provides stability and long-term reusability to the cells without the loss of their activity [10-13]. The encapsulation in polymer matrices is employed as one of the immobilization techniques. In this procedure, a semipermeable polymer controls the biocatalyst, which enables the free entry of substrates and nutrients and exit of waste material. There are various reports on bioreactor studies involving encapsulated cells that exhibit the 


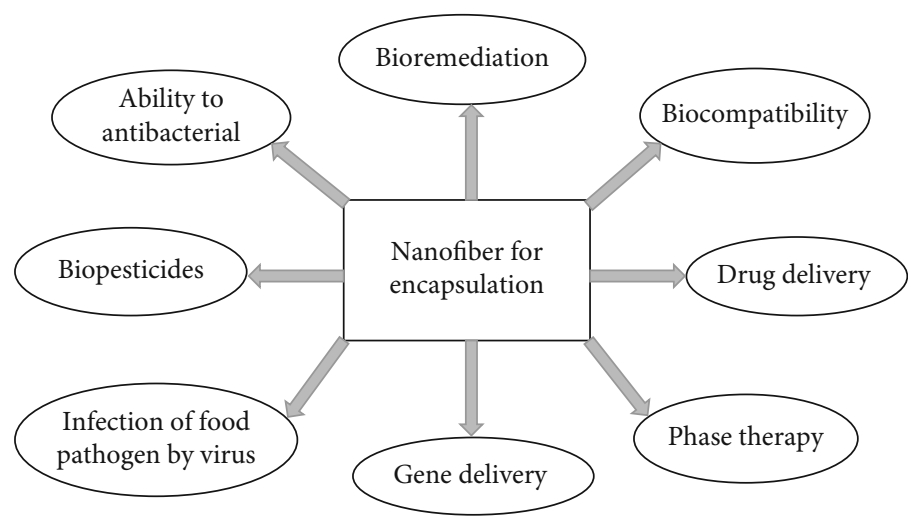

FIGURE 1: Properties of microorganism encapsulated nanofibers.

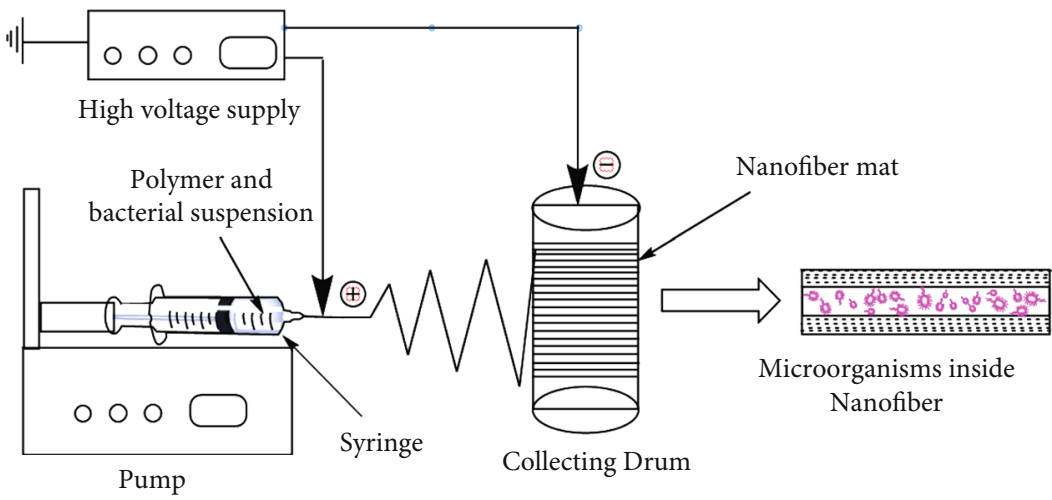

FIgURE 2: Electrospinning machine set-up.

advantages of encapsulation over free cells under different conditions. For example, there has been an increase in the metabolic activity and development of metabolites in addition to the sustainability, protection from toxicants and increase in plasmid activity [14], protection from toxic substances, and increased plasmid stability [10, 15]. The nanofiber has the potential to become a novel porter of immobilization. They possess special and desirable biological properties such as biocompatibility [16], ability to antibacterial [17], nontoxicity [18], carrier drug delivery [19], and bioremediation [20], as shown in Figure 1.

\section{Electrospinning and Characterization Techniques}

The idea of electrospinning dates back to the $16^{\text {th }}$ century which was describe by William Gilbert. Later in 1900s, the process of electrospinning was patented by J. F. Cooley and W. J. Morton. Later, this device was developed which is still very useful in various industries and have numerous applications. Electrospinning is based upon the effect of electrostatic forces on a droplet of liquid polymer or polymer solution. As the electrical force on the droplet increases, it overcomes the force of surface tension holding the droplet and allows the drop to fall towards a conductive collector. The difference in high voltage between the needle tip (spinneret) and the collector causes the droplet to be drawn into a vortex-shaped fiber as the droplet falls through the electric field. The polymer solution in the jet is electrically charged, and its diameter is reduced as the fiber is elongated during the process of spinning. Electrospinning requires a power supply with a high voltage, a small diameter needle syringe, and a conductive collector as shown in Figure 2. Electrospinning is a common method for producing diameter nanofibers within the range of $100 \mathrm{~nm}$ or even less [21-23]. There are two characteristics of electrospinning that make it an efficient process. The first is the extremely fast production of a nanofiber structure (in millisecond scale), and the second is the enormous material elongation rate (of $1000 \mathrm{~s}^{-1}$ order), followed by a decrease in the crosssectional area (of $10^{5}$ order) [19-26]. The advancement of nanofibers has substantially increased the possibilities for meeting today's difficulties. Needle-based electrospinning and needleless electrospinning are the two types of electrospinning systems currently available for generating nanofiber. Multiaxial, coaxial, triaxial, multineedle, bicomponent, and magnetic field-aided electrospinning are some of the other varieties [27]. Apart from these, a new homemade coaxial spinneret with solid core has been introduced recently, which is comprised of two metal capillaries: the epoxy resin adhesive and Teflon solid rod. Stainless steel capillary tubes of sizes $19 \mathrm{G}$ and $25 \mathrm{G}$ were used. Along the tube wall, the $25 \mathrm{G}$ internal capillary was placed into the 19G external capillary. Rubber insulation was used to 
insulate the external tube inlet slot and the internal tube inlet bolt. The $25 \mathrm{G}$ internal tube was used to insert the $0.26 \mathrm{~mm}$ Teflon solid rod, which formed the fluid diversion's "free surface." Despite the presence of a small portion of $19 \mathrm{G}$ external metal tube that was kept outside, all other places that came into contact with the environment were made of insulated polymers. From the slot connected with the 19G external sheath tube, the working fluid was pushed through the syringe. With this modified electrospinning system, aspitin/Eudragit/lecithin hybrid nanofibers were prepared for colon-targeted sustained release of aspirin. This spinneret was designed to produce the nanofibers for the better and control release of the drug or any other molecule which is encapsulated in the nanofiber. Another study found that due to the solubility of polyvinylpyrrolidone (PVP) and ethyl cellulose, the abovementioned homemade eccentric spinneret, which was built for applying side-by-side electrospinning, formed a nanofiber that could offer biphase drug release (EC). The redesigned spinneret's differently shaped nanofibers resulted in a faster burst release in the first phase and a slower sustained release in the second phase [28]. According to another study, the nanofibers were generated using a modified triaxial electrospinning device, which is essentially a DIY trifluid electrospinning apparatus. Three fluid pumps, a high-power supply capable of maintaining $60 \mathrm{kV}$ at $2 \mathrm{~mA}$, a fiber collector, and a removable tri-layer concentric spinneret made up the system. The nanofiber generated by this equipment was a core-shell structural nanofiber (CSF) that was loaded with aspirin and had a longer time period of aspirin-extended-release to prevent drug overdose [29]. New methodologies for manufacturing trilayer depots F2 employing cellulose acetate and acyclovir as the polymer matrix and active ingredient have recently been devised using modified triaxial electrospinning. The nanofiber is made up of three layers and differs from coreshell nanofibers, which have three layers. With a short tailing-off time period, the trilayer F2 might manipulate a better drug-sustained release profile. The proposed concept can be used to build new processes, structures, and performance relationships at the nanoscale for functional applications. The basic encapsulation of cells in single fluid nanofibers can be improved using these strategies. The procedures described above can be used to create core-shell nanofibers in which bacteria or cells can be encased. The cells will become more viable as a result of this, the solvent will have less of an impact on the cells, and it will be able to be stored at lower temperatures for longer periods.

Electrospinning can insert nearly all microorganisms into a polymer matrix resulting in the formation of a composite nanofiber. Every microorganism inside these fibers can be discerned. To chemically characterize the generated nanofibers, the techniques which were used are scanning electron microscopy (SEM), transmission electron microscopy (TEM), Brunauer-Emmett-Teller (BET), and thermal analytical methods such as thermal gravimetry analysis (TGA) and differential scanning calorimetry (DSC) [30]. To validate the nanofiber's functionality and chemical composition, Fourier-transform infrared spectroscopy (FTIR) and nuclear magnetic resonance (NMR) techniques are

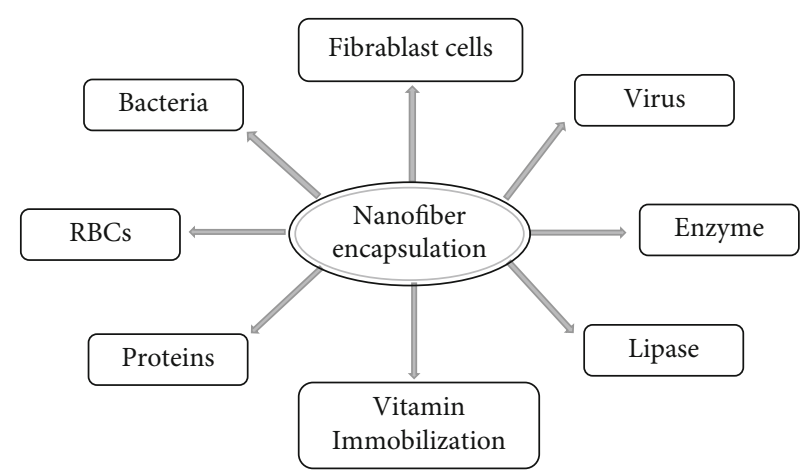

Figure 3: Microorganisms and molecules which can be encapsulated in nanofibers.

employed [31]. The crystallinity of the polymers is studied by X-ray diffraction (XRD) method before and after electrospinning [32]. The technique, X-ray photoelectron spectroscopy (XPS), is used to study the nanofiber's surface chemistry. When the nanofibers are used to encapsulate materials, XPS reveals the amount of encapsulated material immobilizes on the substrate surface [33]. Analysis of the water contact angle shows the hydrophilicity factor or surface hydrophobicity of the nanofibers [34]. Electrospinning has various applications, for example, in tissue engineering, drug delivery, food industry, agriculture, cosmetics, and wastewater treatment [35]. And various molecules such as enzymes [36], proteins [37], viruses [38], vitamins [39], and lipase [40] can be encapsulated or immobilized in the nanofiber which has various applications in different fields as shown in Figure 3. But here, we discuss about the study on the role of nanofiber in microorganism encapsulation and its applications. Also, different nanofibers used for various microorganisms or cells or viruses and their applications are shown in Table 1.

\section{Role of Nanofiber Encapsulated Bacteria in Bioremediation}

Pure water shortage is a worldwide threatening issue; the survival of living organisms and all activities on Earth are absolutely essential. The deposition of effluent water from industries that produce recalcitrant contaminants creates harmful impacts on the atmosphere and human health. Bioremediation is, therefore, an alternative approach to decontaminating water by using microorganisms as it provides cost-effective and sustainable water contaminant remediation and efficient, clean, and green environment. Potential microorganisms are immobilized or encapsulated in nanofibers, resulting in higher catalytic activity, improved stability, and better reusability in wastewater treatment. Nanofibers are also excellent for the task of safe preservation of bioremediating microorganisms for practical applications including wastewater treatment. Nanofiber's usability, flexibility, and cost-effectiveness made microorganisms a promising tool in bioremediation by efficiently removing pollutants from wastewater and other systems [41]. The microorganisms in the nanofibers receive the substrate through the 
TABle 1: Different nanofibers used for different microorganisms and their applications.

\begin{tabular}{|c|c|c|c|}
\hline S.no & Nanofiber used & Microorganisms/cells & Applications \\
\hline 1. & Cellulose acetate nanofibrous web & $\begin{array}{l}\text { Aeromonas eucrenophila, } \\
\text { Clavibactermichiganensis and } \\
\text { Pseudomonas aeruginosa }\end{array}$ & $\begin{array}{l}\text { Decolorization of methylene blue } \\
\text { dye in wastewater treatment }\end{array}$ \\
\hline 2. & Poly caprolactone and polyethylene glycol & Psuedomonas sp. & Atrazine removal \\
\hline 3. & Chitosan & Chlorella vulgaris, Azospirillumbrasilense & Nitrate removal from liquid effluents \\
\hline 4. & Acetate nanofibrous web & Acinetebactorcalcoacetis & $\begin{array}{l}\text { Ammonium removal from the } \\
\text { aquatic environment }\end{array}$ \\
\hline 5. & $\begin{array}{l}\text { PVA/sodium alginate matrix containing } \\
\text { MWCNT }\end{array}$ & Pseudomonas aeruginosa & $\begin{array}{l}\text { Chromium (IV) reduction from } \\
\text { water bodies }\end{array}$ \\
\hline 6. & $\begin{array}{c}\text { Polyethylene oxide (PEO) and Cellulose } \\
\text { diacetate (CDA) }\end{array}$ & Felix O1 Bacteriophage, T4 Phage & $\begin{array}{l}\text { Controlling of food contamination } \\
\text { by Salmonella enteritidis }\end{array}$ \\
\hline 7. & Polyvinyl alcohol (PVA) & Rhizobacteria & Plant growth-promoting \\
\hline 8. & Polyhydroxybutyrate (PHB) & $\begin{array}{l}\text { Caudovirales, Siphoviridae, } \\
\text { Myviridae, Podoviridae }\end{array}$ & $\begin{array}{l}\text { Control growth of E. coli, Salmonella, } \\
\text { Listeria, } \\
\text { Compylobacter, and food packaging }\end{array}$ \\
\hline 9. & $\begin{array}{l}\text { 2-acrylamide-2-methyl propane sulfonic acid } \\
\text { (PAMPS), Polyethylene Oxide (PEO), } \\
\text { and Polyvinyl alcohol (PVA) }\end{array}$ & Trichoderma sp. & $\begin{array}{l}\text { Bioagents to control bacterial and } \\
\text { fungal infection in plants }\end{array}$ \\
\hline 10. & Polyvinyl alcohol (PVA) & 3T3-L1 mice fibroblast cells & Repair of adipose tissue \\
\hline 11. & poly (N-isopropylacrylamide) (PNIPAAm) & RBCs & Single cell diagnostics \\
\hline
\end{tabular}

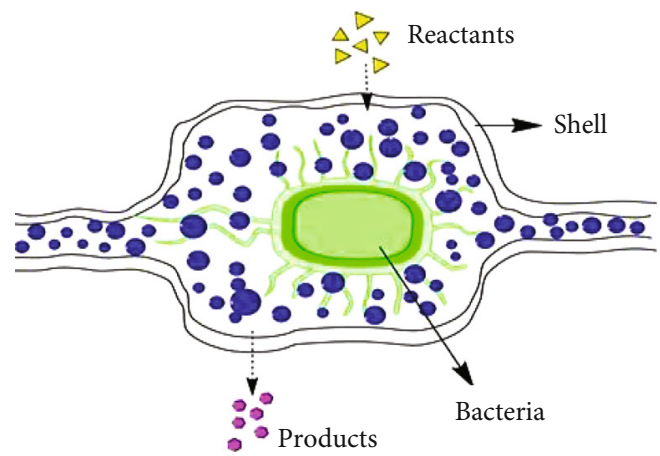

FIGURE 4: A bacterial cell inside the nanofiber.

pores present in the nanofibers, and then, the microorganisms inside the nanofiber convert the reactants into the products and release the products from the pores as shown in Figure 4.

Cai et al. have been reported that nanofiber encapsulated microorganisms can be used to treat wastewater dyes because of their unique properties. This makes nanofibers an ideal system for microorganism immobilization [42]. San et al. confirmed the reusability and decolorization properties of nanofibers in treating water contaminated by methylene blue. Bacteria immobilized nanofiber web (NFW) had achieved 95 percent of dye decolorization before 24 hours, and its reusability study showed 45 percent of dye decolorization effectiveness after four cycles. From these tests, San et al. stated that cellulose acetate nanofibrous web (CANFW) immobilized bacteria may be used repeatedly to extract dyes [43]. Another study was conducted by Mohamed et al. and Sarioglu et al. who examined the bioremediation of methylene blue in the water. Their study sug- gested that web samples encapsulated by the bacteria as nanofiber encapsulation increased the viability of cells [44, 45]. From the above studies, it was concluded that the nanofiber encapsulated microbes are better for the removal of harmful dyes from the dye-contaminated water in comparison to the free cells. The biosensor-based approaches [46, 47], amalgamation of nanotechnology [48], and microbiology have provided an alternative technique for effectively remediating pesticides by immobilizing active microbes in nanofiber. Bioremediation of atrazine through Pseudomonas species adenosine diphosphate (ADP) cells was encapsulated in microtubes containing electrospun nanofibers. Even under nongrowth conditions, the encapsulated cells performed significant atrazine removal bringing potential savings in process operations [49]. These studies suggested that biohybrid nanofibers are ideal materials for removing toxic atrazine from the water system.

The removal of nitrates using nanofibers has also been reported by the encapsulation of algae in nanofibers. The presence of biohybrid content caused the initial removal of nitrate in the liquid. While in further stages, algae used the remaining nitrate in the liquid with a slower growth rate. A study was done by Eroglu et al. to determine the role of chitosan nanofiber in the immobilization of algal cells for nitrate removal. There was an increase in the level of nitrate removal using chitosan nanofiber as compared to free algal cells [50]. Recently, the use of electrospun nanofibrous webs for bacterial or algal immobilization has been reported in ammonium removal. STB/CA performed approximately $48 \mathrm{~h}$ for complete removal of $100 \mathrm{mg} \mathrm{L}^{-1}$ ammonium [51]. Thus, these works elucidate the role of electrospun nanofibers in promising the bioremediation of various contaminants.

The role of nanofibers in the immobilization of microbes for the bioremediation of metal ions has been reported. 
Nanofiber encapsulation ensures the stability and reusability of the microorganism. Pang et al. used multiwalled carbon nanotubes (MCNTs), polyvinyl alcohol (PVA), and sodium alginate to test chromium tolerance of $P$. aeruginosa to exclude $\mathrm{Cr}(\mathrm{VI})$. The immobilized bacteria reduced the $\mathrm{Cr}$ content considerably as compared to the free cells. Therefore, it was concluded that the bacteria's chromium tolerance ability was improved by immobilization [52].

Nevertheless, along with nanoscale porosity, the large surface area makes electrospun nanofiber capable of membranes and filters. And the immobilization of microorganisms in nanofibers with electrospun offers many benefits in bioremediation. With this technology, further work can be done to treat wastewater which could be a greater aid to bioremediation in the environment.

\section{Encapsulation of Phage (Virus) in Nanofiber to Infect Foodborne Pathogens}

The viruses that infect bacteria are called bacteriophages. They are found as abundantly in nature as bacteria. Within aquatic habitats, measured phage density is generally higher as compared to the bacteria. When considering the biosphere environment, they are the most abundant organisms found in nature [53]. A large percentage of bacteriophages belong to the Caudovirales and form a substantial class related to foodborne microbes. Within these, the Siphoviridae family with long, noncontractile tails are $60 \%$ phages, Myoviridae phages with contractile tails are 25\%, and Podoviridae with short tails are 15\% [54]. The Food and Drug Administration (FDA) and the Department of Agriculture (DA) licensed many phage-based products from various companies around the world. These agencies approved many such preparations developed to combat the highly dangerous foodborne pathogens such as E. coli, Salmonella, Listeria, and Campylobacter. The phage-based formulations are also available on a commercial scale. They are added as preservatives in food and meat products (even in live animals) which are readily available [55]. There is a report where the microencapsulated phages were added to pig feed to control the growth of Salmonella typhimurium. The pigs who ingested the feed containing microencapsulated phages disposed less $S$. typhimurium as compared to the other groups and the control [56].

Phage therapy is an important way of preserving and stocking food. Sustained bacteriophage distribution will prevent the growth of the bacteria in various types of food. The coaxial spinning can be used to encapsulate phages to increase their viability. The resulting bio-based electrospun fibers may have potential as food packaging material. There is an example of T4 bacteriophage encapsulation using poly(ethylene oxide) (PEO) and cellulose diacetate (CDA) mixture. This resulted in the increase in diameter of the electrospun fiber and thereby sustaining the prolonged and slower release of T4 phage [57]. Another example of bacteriophageal encapsulation is the encapsulation of phage Felix O1 to provide protection against Salmonella enteritidis. The tests of DSC and TGA showed variations between films and nanofiber films, demonstrating the thermal effect of nanofibers. It is con- cluded that this new packaging method is promising to produce bacteriophagous active packaging. The electrospun nanofiber-mediated encapsulation of bacteriophages has a high potential to be used as a new method in food packaging to control bacterial contamination of foods [58].

\section{Plant Growth-Promoting Bacteria, Biocontrol Agents, and Biopesticide Encapsulation in Electrospun Nanofibers}

Plant-related microorganisms provide their host plant with a broad variety of ecological services, including the acquisition of nutrients and the prevention of diseases. It has been shown that the application of these microorganisms to crops increases crop yield and decreases crop damage from pests. The current work explores the use of the electrospinning process to encapsulate bacterial growth-promoting plants in PVA nanofibers. Bacterial inoculant encapsulation in electrospun nanofibers has enhanced barrier properties against moisture and physical damage, and this process has lower requirements for temperature and pressure compared to other processes. Furthermore, bioactive nanofibers have deferred release that would allow bacteria to gradually release as the seed germinates. In this experiment, three discrete bacterial strains were selected and tested during storage and upon resuspension for their survival and release. There was also a release experiment to determine when the bacteria released from the fibers. The nanofibers generated in this experiment, after one day, showed the greatest release and continued to release for up to 3 days. This technique is a promising approach to preserving bioinoculants on the seed surface, but to achieve long-term survival, additional research into alternative spinning methods and polymer materials will be needed [59].

There are large bioagents such as bacteria, viruses, and fungi that are used to control the growth of other living organisms. These bioagents serve as pathogenic to some other specific organisms. Some of these are regarded as fungicides, some are herbicides, and some of them are insecticides of biological origin. Trichoderma sp. is one of the extensively used biocontrol agents against many plant pathogens [60-62]. To increase the biocontrol agent's efficiency, the immobilization of the same with a biodegradable polymer has to be done. Some polymers are specifically suitable for the preparation of phytopharmaceutical products which are effective and environmentally friendly. For example, chitosan, which is a polysaccharide that is not toxic and degradable, is obtained by deacetylating chitin produced naturally. Chitosan can be broken down by specific enzymes of some of the microorganisms, including bioagents from the Trichoderma sp. Sometimes these polymers can activate the plant defense system [63-66]. Other synthetic polymers are also used for the encapsulation of biocontrol agents. These are PEO, PVA, poly(acrylic acid), polymers, 2-acrylamide-2methyl propane sulfonic acid (PAMPS), and its copolymers with acrylic acid. These provide several advantages to the biocontrol agents such as defense, humidity retention, and microorganism supply of a nutrient medium. Additionally, 
chitosan degradation products activate plant defense functions [67-69]. In one study, electrospinning was done using nanofibrous mats containing chitosan and a useful soil microorganism, Trichoderma viridae. The encapsulation provides protection against the pathogenic Fusarium and Alternaria sp.

\section{Encapsulation of Mammalian Cell for Potential Application in Biomedical Research}

Electrospinning is a potential approach for tissue engineering and biomedical applications because it allows mammalian cells to be incorporated into nanofibers and creates a multilayered cell-nanofiber structure. PVA is electrospun with the 3T3-L1 mouse fibroblast cells. The cells were cultured in Dulbecco's modified Eagle's medium (DMEM). PVA solutions were prepared by mixing PVA in deionized water at $60.8^{\circ} \mathrm{C}$ until homogeneous. Polycaprolactone (PCL) (13 wt.\%) was dissolved in DMF/chloroform (30/70 $w / w)$ or acetone by stirring at $60.8^{\circ} \mathrm{C}$ until homogeneous. Similarly, PCL (10 wt.\%) was dissolved in HFIP by stirring at $50.8^{\circ} \mathrm{C}$ until homogeneous. Prior to electrospinning, the polymer solution (PVA) and cell suspension were mixed in the right ratios and agitated for 5 minutes [70]. Since this electrospinning process necessitates a high voltage, cell viability suffers. Encapsulated cells, on the other hand, can be employed to repair adipose tissue that has been injured.

It is proved that a smart core-sheath nanofiber can collect and release nonadherent cells. The nanofibers are fabricated by single-spinneret electrospinning of poly $(\mathrm{N}$-isopropylacrylamide) (PNIPAAm), polycaprolactone (PCL), and nattokinase (NK) solution blends. PNIPAAm and PCL mixes self-assemble during electrospinning to form coresheath PCL/PNIPAAm nanofibers with PNIPAAm as the sheath. With temperature changes, the PNIPAAm-based core-sheath nanofibers convert from hydrophobic to hydrophilic, improving blood stability. When the nanofibers come into contact with blood, $\mathrm{NK}$ is released to prevent platelet adherence on the nanofiber surface, allowing for direct capture and isolation of red blood cells (RBCs) from the blood above the PNIPAAm phase transition temperature. Meanwhile, the caught RBCs are easily released from the nanofibers in response to temperature stimuli. Up to $100 \%$ release efficiency is achieved, while cellular integrity and function are preserved [71]. This report outlines potential nanofibers for capturing nonadherent cells and releasing them for molecular analysis and single-cell diagnostics.

\section{Conclusion}

Electrospinning is an easy, versatile, and inexpensive technology-based to produce high-volume nanofibers. Electrospinning-generated nanofibers have several advantages such as good encapsulation performance, the regulated dispensing of the encapsulated portion, and increased overall stability, with good safety of the bioactive component. It is an easy and reliable technique for microorganism encapsulation that will be useful, and it has a diverse range of applications along with bioremediation, antimicrobial, and the development of various useful compounds. It is inferred from this study that microorganisms can be used as the basic agents. They have the potential to become a novel porter of immobilization. They possess special and desirable biological properties such as biocompatibility, ability to antibacterial, nontoxicity, carrier drug delivery, and bioremediation. Electrospinning is used to shape the nanofibers by the application of electric field-shaped nanofibers. This device turns the polymer into fine tubes or fibers that can encapsulate certain microorganisms within. Not only microorganisms are encapsulated but also various biological compounds can be encapsulated within these fibers. There can be enzyme immobilization, lipase, vitamin immobilization, antimicrobial immobilization, etc. Besides, the main factor viability of microorganisms increases by encapsulation within the fibers; the microorganisms can remain viable from weeks to months and can be reused. In contrast, the coaxial electrospinning has a major advantage over normal electrospinning to maintain viability, because the coaxial electrospinning technology used the core-shell technique to encapsulate the microorganisms. In core, it contains a mixture of microorganisms along with biodegradable polymers such as polyvinylpyrrolidone (PVP) and PVA, whereas the shell is a nonbiodegradable polymer such as polyvinylidene difluoride (PVDF) and polyvinylidene difluoride-co-hexafluoropropylene (PVDF-HFP) which act as a shield to prevent the loss of viability and the efficacy of microorganisms. Coaxial electrospinning can also initiate control release of bacterial products to synthesize new products and increase the shelf life of the cell which can be used multiple times. Thus, nanofiber's usability, flexibility, and costeffectiveness made microorganisms a promising tool for microbial integration.

\section{Data Availability}

This is not applicable to our review article.

\section{Conflicts of Interest}

The authors declare that they have no conflicts of interest.

\section{References}

[1] P. A. Barrow and J. S. Soothill, "Bacteriophage therapy and prophylaxis: rediscovery and renewed assessment of potential," Trends in Microbiology, vol. 5, no. 7, pp. 268-271, 1997.

[2] J. Alisky, K. Iczkowski, A. Rapoport, and N. Troitsky, "Bacteriophages show promise as antimicrobial agents," The Journal of Infection, vol. 36, no. 1, pp. 5-15, 1998.

[3] F. Liu and L. Huang, "Development of non-viral vectors for systemic gene delivery," Journal of Controlled Release, vol. 78, no. 1-3, pp. 259-266, 2002.

[4] T. Ondarçuhu and C. Joachim, "Drawing a single nanofibre over hundreds of microns," EPL, vol. 42, no. 2, pp. 215-220, 1998.

[5] L. Feng, S. Li, H. Li et al., "Super-hydrophobic surface of aligned polyacrylonitrile nanofibers," Angewandte Chemie 
(International Ed. in English), vol. 41, no. 7, pp. 1221-1223, 2002.

[6] Y. Z. Wan, C. Gao, H. L. Luo et al., "Early growth of nano-sized calcium phosphate on phosphorylated bacterial cellulose nanofibers," Journal of Nanoscience and Nanotechnology, vol. 9, no. 11, pp. 6494-6500, 2009.

[7] P. X. Ma and R. Zhang, "Synthetic nano-scale fibrous extracellular matrix," Journal of Biomedical Materials Research, vol. 46, no. 1, pp. 60-72, 1999.

[8] T. Koga, T. Watanabe, and N. Higashi, "Fabrication of nucleobase-functionalized supramolecular nanofiber through peptide self-assembly," Journal of Nanoscience and Nanotechnology, vol. 9, no. 1, pp. 584-590, 2009.

[9] G. M. Whitesides and B. Grzybowski, "Self-assembly at all scales," Science, vol. 295, no. 5564, pp. 2418-2421, 2002.

[10] M. B. Cassidy, H. Lee, and J. T. Trevors, "Environmental applications of immobilized microbial cells: a review," Journal of Industrial Microbiology, vol. 16, no. 2, pp. 79-101, 1996.

[11] W. Adam, Z. Lukacs, D. Harmsen, C. R. Saha-Möller, and P. Schreier, "Biocatalytic asymmetric hydroxylation of hydrocarbons with the topsoil-microorganism Bacillus megaterium," The Journal of Organic Chemistry, vol. 65, no. 3, pp. 878-882, 2000.

[12] G. A. Dervakos and C. Webb, "On the merits of viable-cell immobilisation," Biotechnology Advances, vol. 9, no. 4, pp. 559-612, 1991.

[13] D. Gadkari, "Nitrification in the presence of soil particles, sand, alginate beads and agar strands," Soil Biology and Biochemistry, vol. 22, no. 1, pp. 17-21, 1990.

[14] H. Keweloh, H.-J. Heipieper, and H.-J. Rehm, "Protection of bacteria against toxicity of phenol by immobilization in calcium alginate," Applied Microbiology and Biotechnology, vol. 31, no. 4, 1989.

[15] C. Knierim, C. L. Greenblatt, S. Agarwal, and A. Greiner, "Blocked bacteria escape by ATRP grafting of a PMMA shell on PVA microparticles," Macromolecular Bioscience, vol. 14, no. 4, pp. 537-545, 2014.

[16] L. Deng, Y. Li, F. Feng, and H. Zhang, "Study on wettability, mechanical property and biocompatibility of electrospun gelatin/zein nanofibers cross-linked by glucose," Food Hydrocolloids, vol. 87, pp. 1-10, 2019.

[17] L. Lin, X. Mao, Y. Sun, G. Rajivgandhi, and H. Cui, “Antibacterial properties of nanofibers containing chrysanthemum essential oil and their application as beef packaging," International Journal of Food Microbiology, vol. 292, pp. 21-30, 2019.

[18] F. A. Sheikh, J. Macossay, T. Cantu et al., "Imaging, spectroscopy, mechanical, alignment and biocompatibility studies of electrospun medical grade polyurethane (Carbothane ${ }^{\mathrm{TM}}$ 3575A) nanofibers and composite nanofibers containing multiwalled carbon nanotubes," Journal of the Mechanical Behavior of Biomedical Materials, vol. 41, pp. 189-198, 2015.

[19] S. Thakkar and M. Misra, "Electrospun polymeric nanofibers: new horizons in drug delivery," European Journal of Pharmaceutical Sciences, vol. 107, pp. 148-167, 2017.

[20] H.-W. Tong, B. R. Mutlu, L. P. Wackett, and A. Aksan, "Manufacturing of bioreactive nanofibers for bioremediation," Biotechnology and Bioengineering, vol. 111, no. 8, pp. 14831493, 2014.

[21] D. H. Reneker and I. Chun, "Nanometre diameter fibres of polymer, produced by electrospinning," Nanotechnology, vol. 7, no. 3, pp. 216-223, 1996.
[22] L. Ji and X. Zhang, "Fabrication of porous carbon nanofibers and their application as anode materials for rechargeable lithium-ion batteries," Nanotechnology, vol. 20, no. 15, article 155705, 2009.

[23] Z. M. Huang, Y. Z. Zhang, M. Kotaki, and S. Ramakrishna, "Compos Sci Technol 63: 2223vol. 3, pp. 0266-3538.

[24] A. L. Yarin, S. Koombhongse, and D. H. Reneker, "Taylor cone and jetting from liquid droplets in electrospinning of nanofibers," Journal of Applied Physics, vol. 90, no. 9, pp. 48364846, 2001.

[25] A. Theron, E. Zussman, and A. L. Yarin, "Electrostatic fieldassisted alignment of electrospun nanofibres," Nanotechnology, vol. 12, no. 3, pp. 384-390, 2001.

[26] S. N. Reznik, A. L. Yarin, E. Zussman, and L. Bercovici, "Evolution of a compound droplet attached to a core-shell nozzle under the action of a strong electric field," Physics of Fluids, vol. 18 , no. 6 , article $062101,2006$.

[27] H. A. Begum and K. R. Khan, "Study on the various types of needle based and needleless electrospinning system for nanofiber production," International Journal of Textile Science, vol. 6 , pp. 110-117, 2017.

[28] A. Gentrurk, E. Kahraman, S. Gungor, Y. Ozsoy, and A. S. Sarac, "Effects of polyvinylpyrrolidone and ethyl cellulose in polyurethane electrospun nanofibers on morphology and drug release characteristics," Turkish Journal of Pharmaceutical Sciences, vol. 17, no. 6, pp. 638-644, 2020.

[29] D. G. Yu, X. Y. Li, X. Wang, J. H. Yang, S. A. Bligh, and G. R. Williams, "Nanofibers fabricated using triaxial electrospinning as zero order drug delivery systems," ACS Applied Materials \& Interfaces, vol. 33, no. 7, pp. 18891-18897, 2015.

[30] F. Kayaci and T. Uyar, "Encapsulation of vanillin/cyclodextrin inclusion complex in electrospun polyvinyl alcohol (PVA) nanowebs: prolonged shelf-life and high temperature stability of vanillin," Food Chemistry, vol. 133, no. 3, pp. 641-649, 2012.

[31] F. Kayaci, O. C. Umu, T. Tekinay, and T. Uyar, "Antibacterial electrospun poly(lactic acid) (PLA) nanofibrous webs incorporating triclosan/cyclodextrin inclusion complexes," Journal of Agricultural and Food Chemistry, vol. 61, no. 16, pp. 39013908, 2013.

[32] F. Kayaci, H. S. Sen, E. Durgun, and T. Uyar, "Functional electrospun polymeric nanofibers incorporating geraniolcyclodextrin inclusion complexes: high thermal stability and enhanced durability of geraniol," Food Research International, vol. 62, pp. 424-431, 2014.

[33] Y. P. Neo, S. Swift, S. Ray, M. Gizdavic-Nikolaidis, J. Jin, and C. O. Perera, "Evaluation of gallic acid loaded zein submicron electrospun fibre mats as novel active packaging materials," Food Chemistry, vol. 141, no. 3, pp. 3192-3200, 2013.

[34] R. Ramaseshan, S. Sundarrajan, Y. Liu, R. S. Barhate, N. L. Lala, and S. Ramakrishna, "Functionalized polymer nanofibre membranes for protection from chemical warfare stimulants," Nanotechnology, vol. 17, no. 12, pp. 2947-2953, 2006.

[35] R. Sridhar, R. Lakshminarayanan, K. Madhaiyan, V. AmuthaBarathi, K. H. C. Lim, and S. Ramakrishna, "ChemInform Abstract: Electrosprayed nanoparticles and electrospun nanofibers based on natural materials: applications in tissue regeneration, drug delivery and pharmaceuticals," ChemInform, vol. 46, no. 15, 2015.

[36] Z.-G. Wang, L.-S. Wan, Z.-M. Liu, X.-J. Huang, and Z.-K. Xu, "Enzyme immobilization on electrospun polymer nanofibers: 
an overview," Journal of Molecular Catalysis B: Enzymatic, vol. 56, no. 4, pp. 189-195, 2009.

[37] Y. Su, Q. Su, W. Liu, G. Jin, X. Mo, and S. Ramakrishn, "Dualdrug encapsulation and release from core-shell nanofibers," Journal of Biomaterials Science. Polymer Edition, vol. 23, no. 7, pp. 861-871, 2012.

[38] B. Loh, V. S. Gondil, P. Manohar, F. M. Khan, H. Yang, and S. Leptihn, "Encapsulation and delivery of therapeutic phages," Applied and Environmental Microbiology, vol. 87, no. $5,2020$.

[39] A. Fahami and M. Fathi, "Development of cress seed mucilage/ PVA nanofibers as a novel carrier for vitamin A delivery," Food Hydrocolloids, vol. 81, pp. 31-38, 2018.

[40] J. Song, D. Kahveci, M. Chen et al., "Enhanced catalytic activity of lipase encapsulated in PCL nanofibers," Langmuir, vol. 28, no. 14, pp. 6157-6162, 2012.

[41] S. Aiswarya Devi, M. Harshiny, and M. Matheswaran, "Role of nanofibers in bioremediation," in Energy, Environment, and Sustainability, pp. 99-114, Springer Singapore, Singapore, 2018.

[42] Z. Cai, Y. Sun, W. Liu, F. Pan, P. Sun, and J. Fu, "An overview of nanomaterials applied for removing dyes from wastewater," Environmental Science and Pollution Research International, vol. 24, no. 19, pp. 15882-15904, 2017.

[43] N. O. San, A. Celebioglu, Y. Tümtaş, T. Uyar, and T. Tekinay, "Reusable bacteria immobilized electrospun nanofibrous webs for decolorization of methylene blue dye in wastewater treatment," RSC Advances, vol. 4, no. 61, pp. 32249-32255, 2014.

[44] A. Mohamed, S. Yousef, M. Ali Abdelnaby et al., "Photocatalytic degradation of organic dyes and enhanced mechanical properties of PAN/CNTs composite nanofibers," Separation and Purification Technology, vol. 182, pp. 219-223, 2017.

[45] O. F. Sarioglu, N. O. S. Keskin, A. Celebioglu, T. Tekinay, and T. Uyar, "Bacteria encapsulated electrospun nanofibrous webs for remediation of methylene blue dye in water," Colloids and Surfaces. B, Biointerfaces, vol. 152, pp. 245-251, 2017.

[46] R. Nagraik, S. Sethi, A. Sharma, D. Kumar, A. Dinesh Kumar, and P. Kumar, "Ultrasensitive nanohybrid electrochemical sensor to detect LipL32 gene of Leptospira interrogans," Chemical Papers, vol. 75, no. 10, pp. 5453-5462, 2021.

[47] R. Nagraik, A. Sharma, D. Kumar, A. Prince Chawla, and P. Kumar, "Milk adulterant detection: conventional and biosensor based approaches: a review," Sens. Bio-Sensing Res., vol. 33, article 100433, 2021.

[48] R. Nagraik, A. Sharma, D. Kumar, S. Mukherjee, F. Sen, and A. P. Kumar, "Amalgamation of biosensors and nanotechnology in disease diagnosis: mini-review," Sensors International, vol. 2, article 100089, 2021.

[49] S. Klein, R. Avrahami, E. Zussman, M. Beliavski, S. Tarre, and M. Green, "Encapsulation of Pseudomonas sp. ADP cells in electrospun microtubes for atrazine bioremediation," Journal of Industrial Microbiology \& Biotechnology, vol. 39, no. 11, pp. 1605-1613, 2012.

[50] E. Eroglu, V. Agarwal, M. Bradshaw et al., "Nitrate removal from liquid effluents using microalgae immobilized on chitosan nanofiber mats," Green Chemistry, vol. 14, no. 10, p. 2682, 2012.

[51] O. F. Sarioglu, O. Yasa, A. Celebioglu, T. Uyar, and T. Tekinay, "Efficient ammonium removal from aquatic environments by Acinetobacter calcoaceticus STB1 immobilized on an electro- spun cellulose acetate nanofibrous web," Green Chemistry, vol. 15, no. 9, p. 2566, 2013.

[52] Y. Pang, G. M. Zeng, L. Tang et al., “Cr(VI) reduction by Pseudomonas aeruginosa immobilized in a polyvinyl alcohol/ sodium alginate matrix containing multi-walled carbon nanotubes," Bioresource Technology, vol. 102, no. 22, pp. 1073310736, 2011.

[53] K. Dabrowska, K. Switała-Jelen, A. Opolski, B. Weber-Dabrowska, and A. Gorski, "Bacteriophage penetration in vertebrates," Journal of Applied Microbiology, vol. 98, no. 1, pp. 713, 2005.

[54] H.-W. Ackermann, "5500 phages examined in the electron microscope," Archives of Virology, vol. 152, no. 2, pp. 227243, 2007.

[55] L. Endersen, J. O’Mahony, C. Hill, R. P. Ross, O. McAuliffe, and A. Coffey, "Phage therapy in the food industry," Annual Review of Food Science and Technology, vol. 5, no. 1, pp. 327-349, 2014.

[56] S. K. Wall, J. Zhang, M. H. Rostagno, and P. D. Ebner, "Phage therapy to reduce preprocessing Salmonella infections in market-weight swine," Applied and Environmental Microbiology, vol. 76, no. 1, pp. 48-53, 2010.

[57] R. Korehei and J. F. Kadla, "Encapsulation of T4 bacteriophage in electrospun poly(ethylene oxide)/cellulose diacetate fibers," Carbohydrate Polymers, vol. 100, pp. 150-157, 2014.

[58] M. J. Costa, J. A. T. Catarina Milho, S. Sillankorva, M. A. Cerqueira, and K. N. Loyd, "Electrospun nanofibres as a novel encapsulation vehicle for Felix O1 bacteriophage for new food packaging applications," 2018.

[59] R. Guo, X. Liu, K. Gao, B. Gao, B. Shi, and Z. Zhen, "Progress in biocontrol research with Trichoderma," Chinese Journal of Biological Control, vol. 18, no. 4, pp. 180-184, 2002.

[60] J. M. Whipps and R. D. Lumsden, "Commercial use of fungi as plant disease biological control agents: status and prospects," Fungal Biocontrol Agents: Progress, Problems and Potential, pp. 9-22, 2001.

[61] S.-I. Aiba, "Preparation of N-acetylchitooligosaccharides by hydrolysis of chitosan with chitinase followed by N-acetylation," Carbohydrate Research, vol. 265, no. 2, pp. 323-328, 1994.

[62] M. Yalpani and D. Pantaleone, "An examination of the unusual susceptibilities of aminoglycans to enzymatic hydrolysis," Carbohydrate Research, vol. 256, no. 1, pp. 159-175, 1994.

[63] D. Pantaleone, M. Yalpani, and M. Scollar, "Unusual susceptibility of chitosan to enzymic hydrolysis," Carbohydrate Research, vol. 237, pp. 325-332, 1992.

[64] A. Yamada, N. Shibuya, O. Kodama, and T. Akatsuka, "Induction of phytoalexin formation in suspension-cultured rice cells by $\mathrm{N}$-acetyl-chitooligosaccharides," Bioscience, Biotechnology, and Biochemistry, vol. 57, no. 3, pp. 405-409, 1993.

[65] O. Stoilova, N. Koseva, T. Petrova, N. Manolova, I. Rashkov, and M. Naydenov, "Hydrolysis of chitosan, chitosan-polyoxyethylene and chitosan-poly(2-acryloylamido-2-methylpropanesulfonic acid) by a crude enzyme complex from Trichoderma viride," Journal of Bioactive and Compatible Polymers, vol. 16, no. 5, pp. 379-392, 2001.

[66] R. I. Mladenova, M. G. Ignatova, M. K. Naydenov, N. E. Manolova, and I. B. Rashkov, "Polyethers with 8-hydroxy-2-quinolinylimine endgroups: preparation, chelating properties and effect on the development of trichodermavirideembeddedin chitosan films," Bulgarian Chemical Communications, vol. 34, no. 2, pp. 112-123, 2002. 
[67] P. Bonina, T. Petrova, N. Manolova, and I. Rashkov, "Degradation of networks composed of chitosan and polyacrylamide by a crude enzyme complex from Bacillus subtilis," E-polymers, vol. 4, no. 1, 2004.

[68] R. Mincheva, N. Manolova, D. Paneva, and I. Rashkov, "Novel polyelectrolyte complexes between $\mathrm{N}$-carboxyethylchitosan and synthetic polyelectrolytes," European Polymer Journal, vol. 42, no. 4, pp. 858-868, 2006.

[69] M. Spasova, N. Manolova, M. Naydenov, J. Kuzmanova, and I. Rashkov, "Electrospun biohybrid materials for plant biocontrol containing chitosan and Trichoderma virides pores," Journal of Bioactive and Compatible Polymers, vol. 26, no. 1, pp. 48-55, 2011.

[70] M. F. Canbolat, C. Tang, S. H. Bernacki, B. Pourdeyhimi, and S. Khan, "Mammalian cell viability in electrospun composite nanofiber structures," Macromolecular Bioscience, vol. 11, no. 10, pp. 1346-1356, 2011.

[71] Q. Shi, J. Hou, C. Zhao et al., "A smart core-sheath nanofiber that captures and releases red blood cells from the blood," Nanoscale, vol. 8, no. 4, pp. 2022-2029, 2016. 